\title{
Potentiators of Disease During Barley Infection by Pyrenophora teres f. teres in a Susceptible Interaction
}

\author{
Paula Moolhuijzen, Julie A. Lawrence, and Simon R. Ellwood ${ }^{\dagger}$ \\ Centre for Crop and Disease Management, School of Molecular and Life Sciences, Curtin University, Bentley, WA 6102, \\ Australia
}

Accepted 8 March 2021.

\begin{abstract}
Pyrenophora teres f. teres is a necrotrophic fungal pathogen and causal agent of net form net blotch (NFNB), a significant disease of barley. RNA-seq data encompassing asymptomatic and subsequent necrotrophic phases of the pathogen was obtained for $P$. teres $\mathrm{f}$. teres isolate W1-1 in NFNB-sensitive cultivar Baudin. Host genes notably regulated during infection included concerted induction of over half the repertoire of disease resistance genes, together with genes involved in oxidation-reduction processes, characteristic of a hypersensitive response. Several systemic acquired resistance response genes were suppressed and there was a complete absence of defense-related thionin gene expression. In $P$. teres f. teres, genes involved in hydrolase activities and cell-wall catabolic processes were induced during infection, while nitrate assimilation and response to oxidative stress processes were suppressed. Timecourse data allowed a number of predicted $P$. teres f. teres effector genes with differing expression profiles to be identified that may underlie barley sensitivity to NFNB. Candidate genes involved in the host-pathogen interaction provide a basis for functional characterization and control strategies based on fungicide or mutation targets, which will facilitate further research aimed at controlling NFNB disease.
\end{abstract}

Keywords: Hordeum vulgare, necrotrophic fungal pathogen, phytotoxins, RNA sequencing

Pyrenophora teres f. teres [anamorph Drechslera (Sacc.) Shoemaker] is a necrotrophic ascomycete that causes net form net blotch (NFNB) in barley (Hordeum vulgare). A widespread and destructive disease of barley crops worldwide, NFNB can cause yield losses of up to $40 \%$ in susceptible cultivars (Murray and Brennan 2010). In South Australia, in the absence of fungicide treatment, yield losses up to $70 \%$ were observed, with $100 \%$ losses after the removal of undersized grain that is unsuitable for malting (Wallwork et al. 2016). P. teres f. teres is a genetically

${ }^{\dagger}$ Corresponding author: S. R. Ellwood; Simon.Ellwood@curtin.edu.au

Funding: This research was funded under Grains Research and Development Corporation (GRDC) grant CUR00023. Research was supported by the Centre for Crop and Disease Management, a cooperative research vehicle of the GRDC and Curtin University.

*The $e$-Xtra logo stands for "electronic extra" and indicates there are supplementary materials published online.

The author(s) declare no conflict of interest. diverse pathogen (Ellwood et al. 2019; Liu et al. 2012), with the progeny of two parents showing new virulence combinations, potentially making development of resistant cultivars a challenge (Jalli 2011).

The infection process of $P$. teres f. teres on susceptible leaves starts when conducive conditions of temperature and humidity encourage germination of conidia within $6 \mathrm{~h}$ of inoculation (Lightfoot et al. 2017). In the asymptomatic or biotrophic phase of infection, mycelial penetration of the leaf epidermal cells followed by growth through underlying mesophyll cells occurs within 1 and 2 days respectively. The first sign of necrosis in epidermal and mesophyll cells is observed within 3 days and, by 5 days, cell death and chlorosis is widespread (Lightfoot et al. 2017). Symptoms of NFNB leaf disease are elongated brown lesions, containing a characteristic reticulated pattern of darkbrown necrotic regions.

Barley has an innate defense system against fungal pathogens. These include pathogen-associated molecular pattern-triggered immunity (PTI) and effector-triggered immunity (ETI) in response to proteins secreted by the pathogen. The primary response to pathogen recognition is the hypersensitive response (HR) in plant epidermal cells that follows the release of nitric acid and reactive oxygen species (ROS), such as hydrogen peroxide, superoxide, and hydroxyl radicals. HR is commonly associated with inhibition of biotrophic pathogens as localized cell death removes the supply of nutrients. However, this inadvertently provides nutrients directly from the dead cells to necrotrophic pathogens such as $P$. teres f. teres.

Many studies have investigated the barley- $P$. teres $\mathrm{f}$. teres host-pathogen interaction using barley biparental mapping populations and genome-wide association studies (GWAS). These studies have suggested complex genetic interactions involving both minor and major barley host resistance genes, while $P$. teres $\mathrm{f}$. teres possesses an array of virulence genes that promote disease (Koladia et al. 2017a and b; Martin et al. 2020; Richards et al. 2017). Furthermore, partial purification of a small phytotoxic proteinaceous effector (PttNE1) and genetic mapping of the corresponding sensitivity gene (SPN1) indicated that an inverse gene-for-gene model, shared with other plant-necrotrophic pathogens, exists in this pathosystem (Faris and Friesen 2020; Liu et al. 2015; Shjerve et al. 2014).

Two previous barley- $P$. teres $\mathrm{f}$. teres in-planta studies using proteomics approaches identified $222 P$. teres f. teres proteins via gel electrophoresis (Ismail and Able 2016, 2017) and 140 barley proteins via mass spectrometry (Hassett et al. 2020). However, a genome-wide transcriptome analysis of gene expression has not been reported to date. This study utilizes highquality reference genome assemblies and an RNA sequencing (RNA-seq) approach to investigate RNA expression in P. teres f. teres, using isolate W1-1 (Syme et al. 2018) and NFNB 
susceptible cultivar Baudin, at 2, 3, 5, and 7 days postinoculation (dpi). The susceptible interaction between W1-1 and Baudin was chosen to study unimpeded disease progression, with the objective of gaining insights into mechanisms of pathogen virulence and ineffective host defense pathways or channels of subversion by the pathogen. This was achieved by a timecourse study of differentially regulated gene expression profiles together with changes in metabolic pathways and cellular processes.

\section{RESULTS}

Overview of changes in $P$. teres f. teres W1-1 gene expression during barley cv. Baudin infection.

Total RNA reads from each timepoint were aligned to the genome sequence of $P$. teres f. teres W1-1 (Supplementary Table S1). The percentage of concordant read alignments ranged from $0.13 \%$ at 2 dpi to $5.04 \%$ at 7 dpi (Table 1). A principal component analysis (PCA) showed that the greatest variance of $72 \%$ was observed between 2- and 7-dpi samples and only $12 \%$ variance was explained on the second component (Supplementary Fig. S1). Of the total 11,561 W1-1 genes, over $70 \%$ were expressed in the samples.

During $P$. teres f. teres infection of barley, a total of 2,085 $P$. teres f. teres genes were found to be significantly differentially expressed (Supplementary Table S2) and, of these, 1,362 were up-regulated and 723 were down-regulated. The distribution of significantly regulated genes was across all $P$. teres f. teres chromosomes (Supplementary Fig. S2).

\section{Roles of $P$. teres f. teres W1-1 genes with significant expression changes during barley infection.}

Significantly regulated genes in $P$. teres $\mathrm{f}$. teres during infection of barley from 2 to 7 dpi were investigated to identify any enrichments for particular molecular functions (MF) and biological processes (BP) (Supplementary Table S3) via associated gene ontology (GO) terms. MF notably enriched for induced genes were for $\alpha$-glucuronidase, cellulose binding, cellulase, dipeptidyl-peptidase, glycerone kinase (EC 2.7.1.29), cation/ sodium ion symporter, and pectinesterase activities. Hydrolase activities (GO:0004553 and GO:0016798) were the most significant MF GO terms ( $P$ value 1e-30) for induced genes. For suppressed genes, enriched MFs included ammonium transmembrane transporter, oxidoreductase, peroxidase, primary amine oxidase, quinone binding, serine-type carboxy/exo peptidase, and starch binding activities (Fig. 1A). Transmembrane transporter activity (GO:0022857) was found to be the most significant MF GO term $(P$ value $6.4 \mathrm{e}-10)$ for suppressed genes.

BP associated with induced genes included alditol metabolism, cell-wall modification, and catabolism of amines/biogenic amines, cell walls, cellulose, hemicellulose, polysaccharides (cellular), glucan, tryptophan, and xylan. Furthermore, neurotransmitter transport processes were found induced. Carbohydrate metabolic process (GO:0005975) was the most significant enrichment ( $P$ value 1e-30) found for induced genes. Genes with suppressed expression were enriched in ammonium transport, nitrate assimilation, nitrogen cycle, reactive nitrogen species metabolic processes, and response to oxidative stress metabolic processes. Transmembrane transport processes were found to be the most significant enrichment ( $P$ value $4.7 \mathrm{e}-10)$ for suppressed genes (Fig. 1B).

In summary, $P$. teres $\mathrm{f}$. teres showed significant gene induction for plant cell and polysaccharide catabolic activities and significant suppression of ammonium transport, nitrate assimilation, reactive nitrogen species processes, starch and chitin binding, and response to oxidative stress (peroxidase activity) functions.

The top induced gene based on the greatest fold change in expression across all sample groups was a glucanase gene (Ptt_W11.g08601) with a $\log _{2}$ fold change of 13.775 , while a cytochrome P450 gene (Ptt_W11.g05213) had the greatest downregulated $\log _{2}$ fold change of -9.607 . This downregulation was the most significant at $7 \mathrm{dpi}$, relative to $2 \mathrm{dpi}$, timepoint (Supplementary Fig. S3). P. teres f. teres has a large glucanase family of 18 genes and, of these, 14 genes were significantly induced during infection (Fig. 2).

\section{$P$. teres f. teres gene expression profiles during barley infection.}

To relate expression profile patterns to any particular biological functions or processes, a total of 1,470 differentially expressed genes clustered into 14 different expression profile groups C1 to C14 (Fig. 3; Supplementary Table S4). Generally, expression profiles $\mathrm{C} 1$ to $\mathrm{C} 3, \mathrm{C} 5$, and $\mathrm{C} 6$ had an increase in expression over the four timepoints and were significantly enriched for hydrolase, lyase, transferase and transporter activities, and carbohydrate metabolism. Furthermore, C1 and C2 had significant enrichment for hydrolase activity/glycosidase (GO:0016798), which included plant cell-wall degradation enzymes, cutinases, galactosidases, xylosidases, aldose epimerases, glucosidases, and glucanases. Fungal adhesion proteins (containing CFEM domains) were identified in C5 and C13, and jacalin domain proteins (host binding proteins) were identified in the $\mathrm{C} 1$ expression profile. Transmembrane transporter activities (GO:0005215) were significantly enriched in C11. A number of gene expression profiles peaked at 3 dpi (C6, C9, C10, and $\mathrm{C} 11)$ that were enriched for transporter $(\mathrm{C} 6, \mathrm{C} 9$, and $\mathrm{C} 11)$ and oxidoreductase activities (C10). Gene expression profiles that peaked at 5 dpi were enriched for iron binding (C7) and antioxidant activity $(\mathrm{C} 8)$. The expression profile groups $\mathrm{C} 12$ to C14 were enriched for oxidoreductase and structural molecular activities and exhibited a decrease in expression after 2 dpi. Predicted effectors were found in all profiles.

\section{Regulation of $\boldsymbol{P}$. teres $\mathrm{f}$. teres biosynthetic gene clusters during infection.}

Three biosynthetic gene clusters were identified that showed significant induced expression during infection, which were all

Table 1. Pyrenophora teres f. teres isolate W1-1 RNA read sequences and alignment metrics ${ }^{\mathrm{a}}$

\begin{tabular}{|c|c|c|c|c|c|c|c|c|c|c|c|c|}
\hline \multirow[b]{2}{*}{ Parameter } & \multicolumn{3}{|c|}{2 dpi } & \multicolumn{3}{|c|}{3 dpi } & \multicolumn{3}{|c|}{5 dpi } & \multicolumn{3}{|c|}{7 dpi } \\
\hline & S1 & S2 & S3 & S5 & S6 & S8 & S9 & S10 & S11 & S13 & S14 & S15 \\
\hline Read pairs $(\mathrm{M})$ & 206 & 190 & 172 & 173 & 165 & 184 & 180 & 200 & 179 & 189 & 195 & 173 \\
\hline Aligned uniquely (K) & 1,869 & 1,519 & 222 & 1,101 & 1,572 & 1,752 & 3,366 & 3,491 & 2,808 & 6,152 & 6,735 & 8,762 \\
\hline$\%$ Aligned uniquely & 0.91 & 0.80 & 0.13 & 0.64 & 0.95 & 0.95 & 1.86 & 1.74 & 1.57 & 3.25 & 3.44 & 5.04 \\
\hline Aligned to multiple loci & 121,929 & 186,719 & 74,863 & 87,370 & 98,142 & 91,686 & 172,624 & 563,226 & 146,530 & 395,226 & 471,425 & 543,617 \\
\hline$\%$ Aligned to multiple loci & 0.06 & 0.10 & 0.04 & 0.05 & 0.06 & 0.05 & 0.10 & 0.28 & 0.08 & 0.21 & 0.24 & 0.32 \\
\hline Genes $^{\mathrm{b}}$ & 8,189 & 7,846 & 3,947 & 7,836 & 8,377 & 8,448 & 8,843 & 8,980 & 8,752 & 9,222 & 9,316 & 9,462 \\
\hline
\end{tabular}

a dpi = days postinoculation.

b Number of W1-1 genes expressed with read pair counts $\geq 10$. 

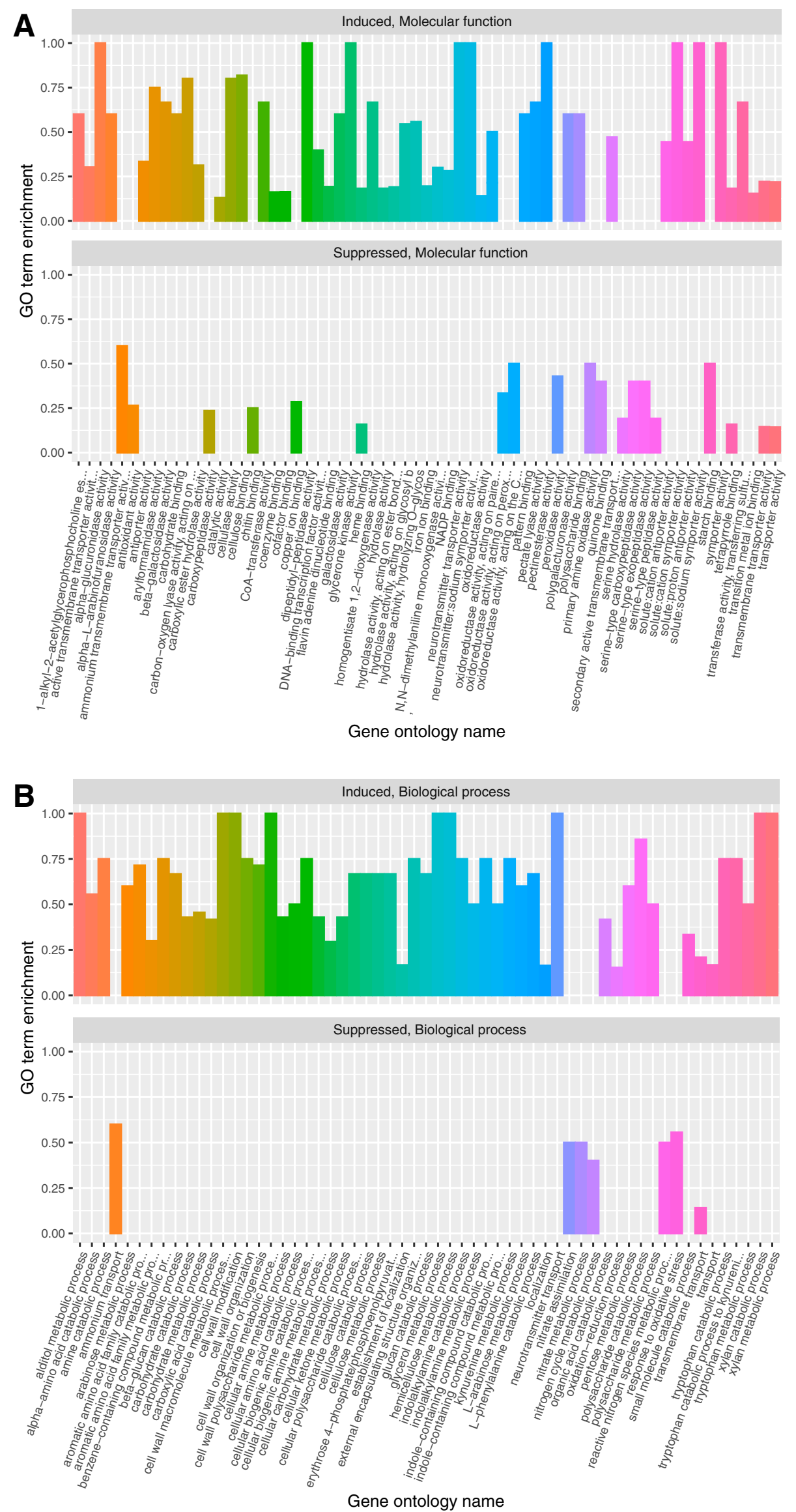

Fig. 1. Pyrenophora teres f. teres isolate W1-1 gene ontology (GO) terms enriched for genes significantly up- and down-regulated. A, Molecular function. B, Biological processes. Significant GO terms are filtered for ratios $\geq 0.12$ for visualization. 
located close to the subtelomeric regions of chromosomes 1, 3, and 10. These included a nonribosomal peptide synthase (NRPS) (Ptt_W11.g00791, Ptt_W11.g00794, Ptt_W11.g00795) located on chromosome 1 (3,234,906 to $3,413,185 \mathrm{bp})$, a NRPS biosynthetic gene cluster (Ptt_W11.g03150, Ptt_W11.g03165, Ptt_W11.g03170, Ptt_W11.g03171, Ptt_W11.g03174) on chromosome 3 (891,703 to $1,228,860$ bp) located close to a known NFNB quantitative trait locus (QTL) (QTL4) (Martin et al. 2020), and a T1-polyketide synthase (PKS) (Ptt_W11.g10391 and Ptt_W11.g10392) biosynthetic gene cluster on chromosome 10 (2,316,961 to 2,378,086 bp). A predicted hybrid-like PKS/NRPS biosynthetic gene cluster (Ptt_W11.g05203 to

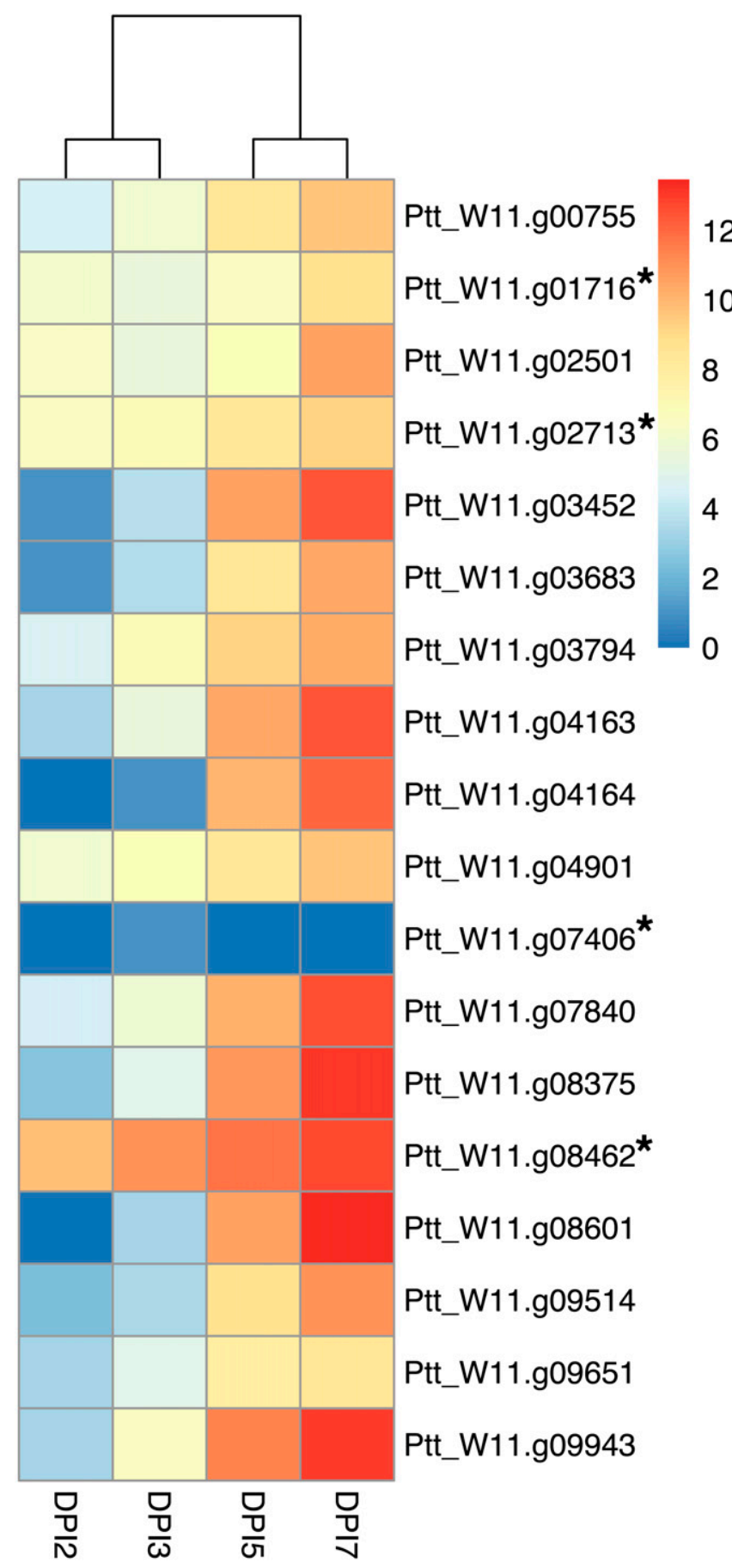

Fig. 2. Pyrenophora teres f. teres isolate W1-1 glucanases/endoglucanase gene expression $\log _{2}$ values (average expression) at 2, 3, 5, and 7 days postinoculation on barley. Asterisks (*) indicate genes not significantly differentially expressed at fold change $\geq 2$ and adjusted $P$ value $\leq 0.05$.
Ptt_W11.g05214) was significantly suppressed after 2 dpi (Supplementary Fig. S4) on chromosome $4(2,693,035$ to 2,746,217 bp).

Putative $P$. teres f. teres effector expression during barley infection.

Significantly expressed $P$. teres f. teres genes were screened for small, secreted protein (SSP) candidates, otherwise known as putative effectors. A total of 380 genes were identified as putative effector proteins, and, of these, 222 were induced and 158 were suppressed during NFNB (Fig. 4; Supplementary Table S5).

\section{Effector candidate expression}

in $P$. teres $\mathbf{f}$. teres virulence QTLs.

A total of 85 genes within known P. teres $\mathrm{f}$. teres virulence QTL regions (Martin et al. 2020) were investigated, and 16 genes showed significant differential expression (Supplementary Table S5). However, of these, only four genes were identified for two cv. Beecher QTLs, which are shared by isolate W1-1. Chromosome 1 QTL1 genes included a predicted effector, Ptt_W11.g00009 (672,638 to 673,055 bp), and a hypothetical protein, Ptt_W11.g00013 (681,919 to $682,831 \mathrm{bp})$, which were both induced. On chromosome 3, QTL7 genes included an induced predicted effector/DJ-1 (damage protection) protein $(3,977,816$ to $3,978,790 \mathrm{bp})$ and a suppressed plastidic glucose transporter 4 protein $(4,001,618$ to $4,003,449 \mathrm{bp})$.

\section{Overview of changes in Baudin gene expression during $P$. teres f. teres W1-1 infection.}

Total RNA reads for each timepoint were aligned to the genome sequence of barley (Beier et al. 2017; Howe et al. 2020) and over 130 million reads (greater than 80\%) were mapped for each sample (Supplementary Table S1). A PCA showed that the greatest variance of $86 \%$ was observed between 2 - and 7-dpi samples, and only $2.7 \%$ of the variance could be explained by the second component (Supplementary Fig. S5). From a total of 39,841 barley genes, 22,136 (55\%) were expressed at $\geq 30$ read alignments per sample. Expressed gene distributions across all seven barley chromosomes were generally sparser in centromeric regions, in which gene density is lower (Supplementary Fig. S6).

During P. teres f. teres infection of barley, a total of 3,738 barley genes were found significantly differentially expressed, of these, 1,910 were up-regulated and 1,828 were down-regulated (Supplementary Table S2). The top 20 regulated genes based on the greatest fold changes in expression across all sample groups are shown in Supplementary Table S2. The greatest induced fold change was for a hypothetical gene (HORVU2Hr1G119250) with a $\log _{2}$ fold change of 13.229 . HORVU2Hr1G119250 is located on chromosome $2 \mathrm{H}(744,765,164$ to $744,776,498 \mathrm{bp}$ ) with no paralogous genes in the barley genome (Supplementary Fig. S7A). A terpene synthase (HORVU6Hr1G012170), which had the greatest downregulated $\log _{2}$ fold change of -13.7474 , is located on chromosome $6 \mathrm{H}$ $(23,200,249$ to $23,204,378 \mathrm{bp})$ and has 24 paralogous genes in the barley genome (Supplementary Fig. S7B). This downregulation was most significant at 7 dpi relative to the 2-dpi timepoint.

\section{Roles of barley genes with significant expression changes} during $P$. teres f. teres infection.

Barley genes significantly induced during infection by $P$. teres f. teres W1-1 (Supplementary Table S3) were enriched for MF that involved catechol oxidase activity, oxidoreductase activity acting on diphenols, and catalytic activity (GO:0003824). Catalytic activity was identified as the most significant $(P$ value 5e-16) MF GO term associated with induced genes. Suppressed genes had MF enriched for aspartate, $\alpha$-glucosidase and amino 
acid kinase activities, glutathione peroxidase activity, protochlorophyllide reductase activity, sucrose $\alpha$-glucosidase activity, DNA-3-methyadenine glycosylase activity and fatty acid binding. The most significant MF GO term found for suppressed genes was protein heterodimerization activity (GO:0046982) ( $P$ value 1e-30) (Fig. 5A).

BP enriched among induced genes in barley were proline, pyrimidine nucleobase and glutamine catabolic processes, cellular response to nitrogen levels, and mitochondrial calcium ion homeostasis. Oxidation-reduction processes (GO:0055114) were found to be the most significant BP GO term associated with induced genes $(P$ value $8.4 \mathrm{e}-05)$. Suppressed BP included chlorophyll biosynthesis, photosynthesis, and phototropism. However, the suppression of DNA packaging process (GO:0006323) was the most significant ( $P$ value $7.8 \mathrm{e}-15)$ (Fig. 5B).
In summary, barley responses showed an increase in the expression of catechol oxidase activity, cellular response to $\mathrm{N}$ levels and oxidation-reduction processes, and a decrease in amino acid kinase activities, DNA methyl base glycosylase activity (DNA packaging), fatty acid binding, and photosynthesisrelated processes.

Barley gene expression profiles

during $P$. teres $\mathrm{f}$. teres infection.

The expression profiles for significantly expressed barley genes clustered into 13 groups (C1 to C13) (Fig. 6; Supplementary Table S6). Generally, the genes present in $\mathrm{C} 1$ to $\mathrm{C} 6$ were involved in suppression of aspartate kinase activity, chlorophyll and fatty acid binding and biosynthesis, phototropism, carbon fixation, DNA binding, protein-chromophore
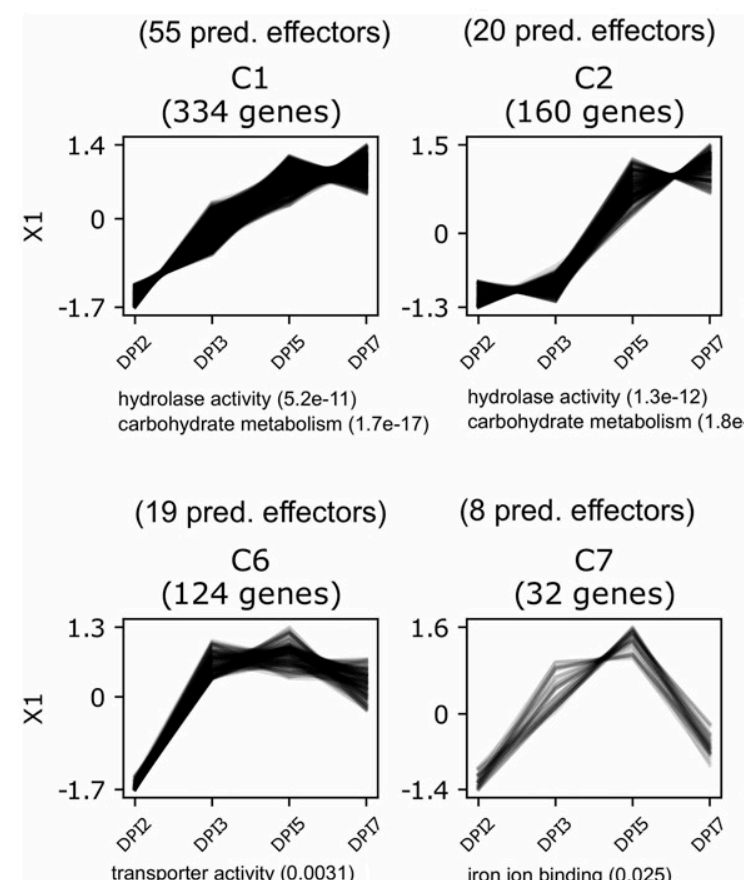

(1 pred. effectors)

C11

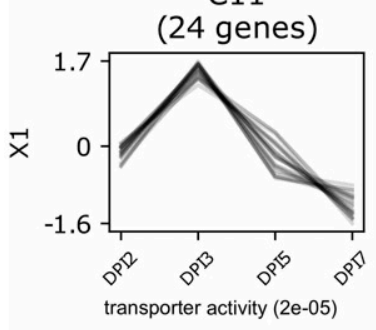

(8 pred. effectors)

C7 (32 genes)

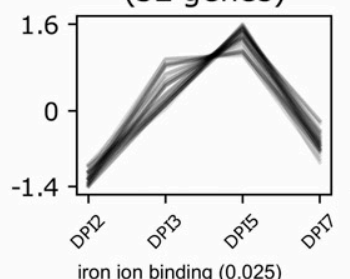

(39 pred. effectors)

C12 (97 genes)

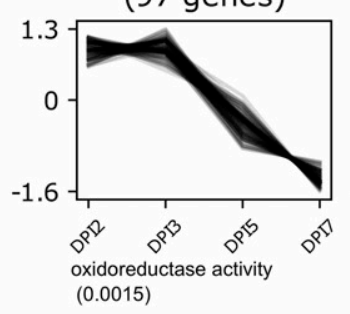

(11 pred. effectors)

C3

(67 genes)

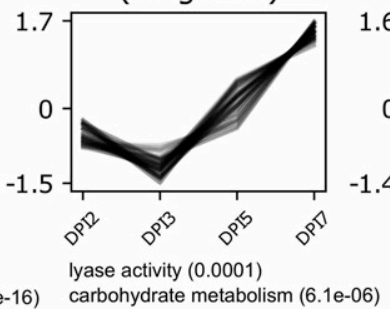

(5 pred. effectors)

C4 (25 genes)

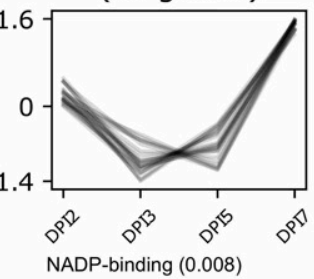

NADP-binding (0.008)
(6 pred. effectors)

C5 (48 genes)

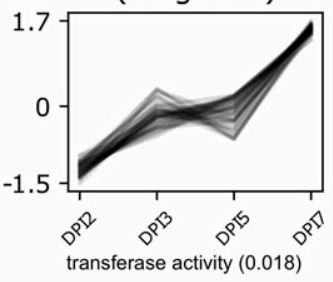

(9 pred. effectors)

C8

(53 genes)

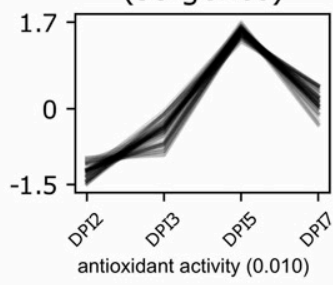

(52 pred. effectors)

C13 (341 genes)

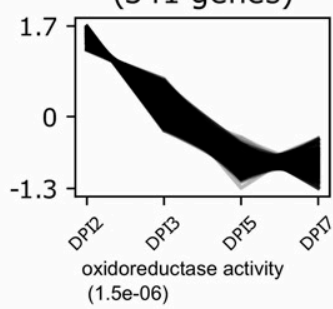

(7 pred. effectors)

C9

(32 genes)

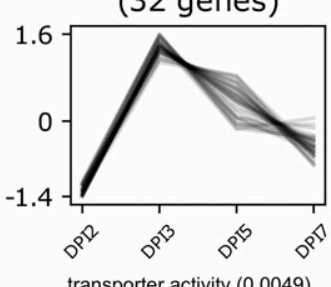

(2 pred. effectors)

C10

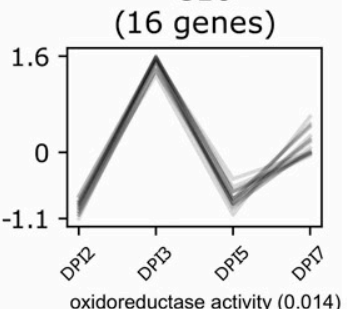

(27 pred. effectors)

C14 (117 genes)

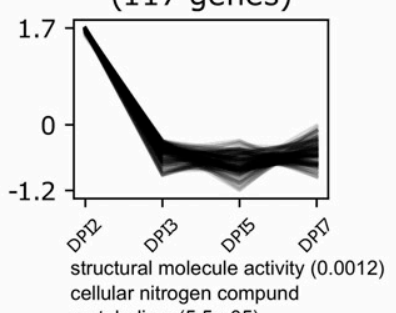

cellular nitrogen compund metabolism (5.5e-05)

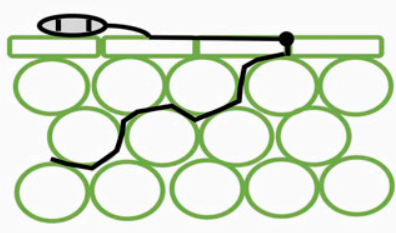

$2 \mathrm{dpi}$

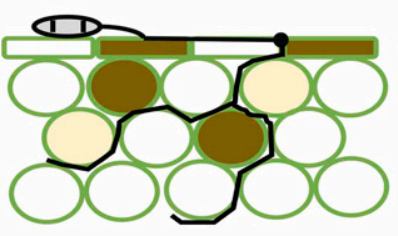

$3 \mathrm{dpi}$

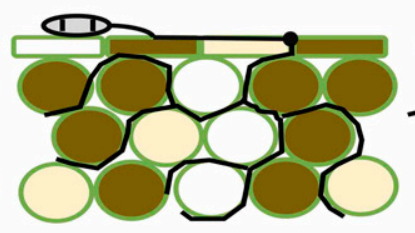

5 dpi

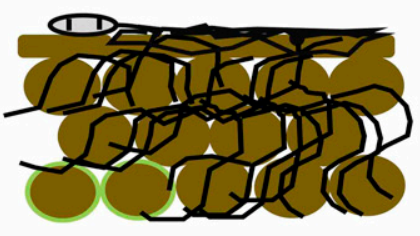

$7 \mathrm{dpi}$

Fig. 3. Pyrenophora teres f. teres isolate W1-1 gene expression profiles during infection of barley between 2 and 7 days postinoculation (dpi). Expression profile groups $\mathrm{C} 1-\mathrm{C} 14$ are depicted and a schematic of P. teres f. teres leaf infection from 2 to 7 dpi is shown at the bottom, modified from Lightfoot et al. (2017). 
linkage, sesquiterpenoid biosynthesis, auxin-activated signaling, phototropism, and responses to water and karrikin during infection. Gene cluster profiles for C7 to $\mathrm{C} 13$ had induced expression patterns containing genes involved in oxidoreductase processes (C11 and $\mathrm{C} 12)$, carbohydrate binding (C11), calcium ion binding (C11), copper ion binding ( $\mathrm{C} 12)$, iron ion binding (C12), heme binding (C10), chitin binding (C13), serine-type endopeptidase inhibitor activity (C9), chitin and cell-wall macromolecule catabolic processes (C13), and syncytium formation (C13). Several profile patterns changed significantly at $3 \mathrm{dpi}$, when the infection phase transitions from asymptomatic to necrotrophic $(\mathrm{C} 2, \mathrm{C} 3, \mathrm{C} 4$, $\mathrm{C} 5, \mathrm{C} 7, \mathrm{C} 8, \mathrm{C} 12$, and C13), representing 1,016 genes.

To better understand defense mechanisms underlying barley gene expression during $P$. teres f. teres infection, highly regulated and constitutively expressed defense-related genes were further investigated.

\section{Barley defense activation during NFNB.}

Barley pathogen sensing, signaling, and putative disease-resistance genes were significantly regulated during $P$. teres $\mathrm{f}$. teres infection. These included 226 receptor-like protein kinase genes $(R L K \mathrm{~s}), 24$ with nucleotide-binding NB-ARC domains, 69 leucine-rich repeat (LRR) domain-containing proteins, and two Mlo-like proteins. Only three genes (HORVU2Hr1G089020, HORVU3Hr1G013270, and HORVU3Hr1G100990) were found in both NB-ARC (IPR002182) and LRR (IPR001611) protein categories based on InterPro identifiers (Quevillon et al. 2005). A total of 173 transcription factors were also differentially

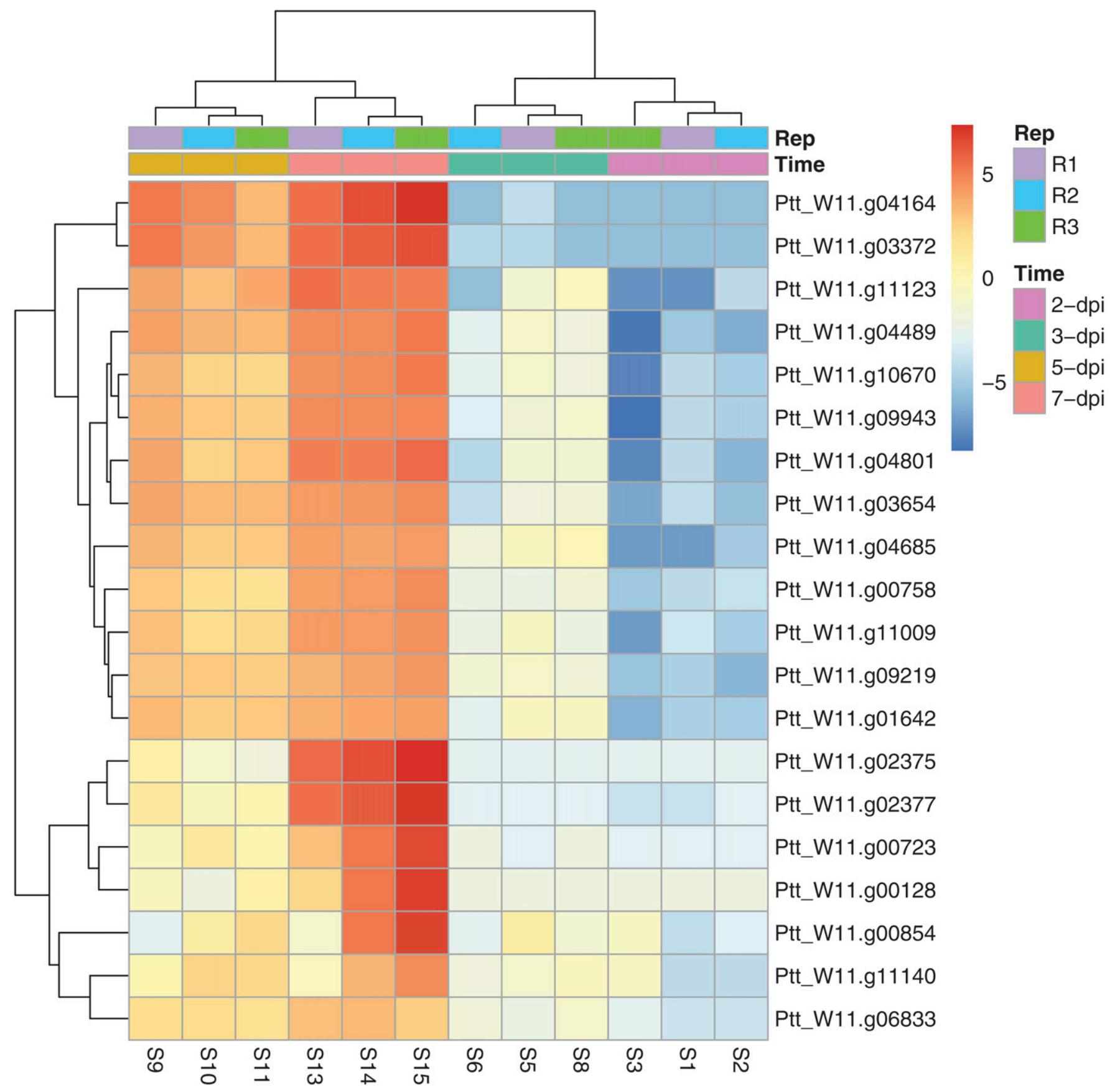

Fig. 4. Top 20 expressed Pyrenophora teres f. teres isolate W1-1 predicted effectors ( $\log _{2}$ scale of expression minus mean expression) during infection of barley. 

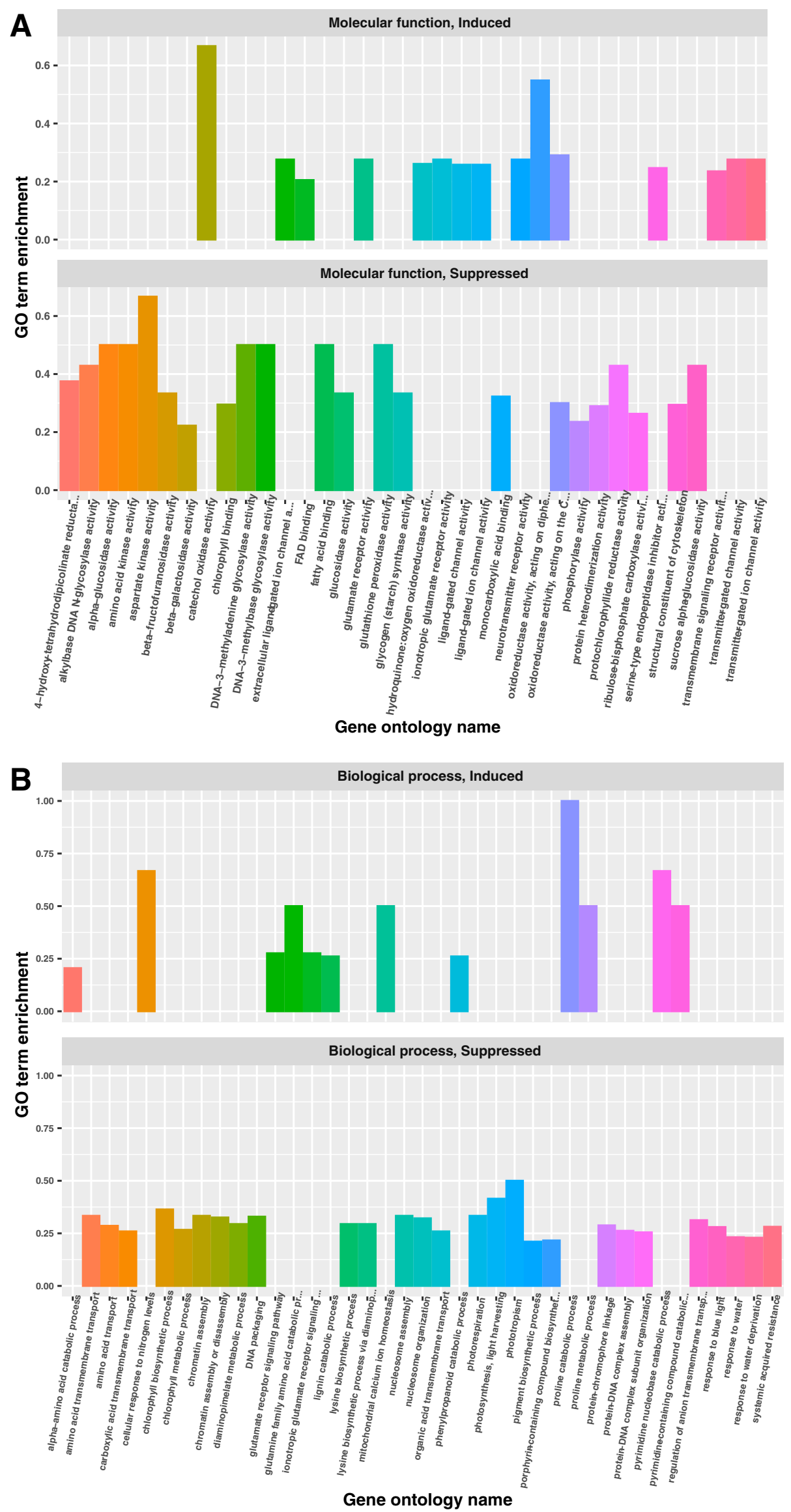

Fig. 5. Barley gene ontology (GO) terms associated with genes significantly induced and suppressed during infection of cultivar Baudin with Pyrenophora teres f. teres isolate W1-1. A, Molecular functions. B, Biological processes. Significant GO term ratios $\geq 0.2$ are displayed for visualization. 
expressed; these included WRKY, SANT, MYB, and zinc-finger $\mathrm{C} 2 \mathrm{H} 2$-type domain-containing proteins (Table 2).

Two known barley disease resistance genes identified through GrainGenes (Blake et al. 2019), the nucleotide binding site-LRR rga (HORVU7Hr1G118440) and the stem rust resistance protein rpg1 (HORVU7Hr1G001450), with genome data were also examined for expression during NFNB. During infection, rga was found to be highly but not significantly differentially expressed and rpgl had a complete absence of expression.

\section{Barley defense response-related proteins} during $P$. teres f. teres infection.

A total of 15 of 17 known pathogenesis-related (PR) protein groups were found to have genes significantly upregulated during $P$. teres $\mathrm{f}$. teres infection (Table 3 ). These included seven PR-1 cysteine-rich secretory CAP domain-containing proteins (PF00188), 16 PR-2 glycoside hydrolase family 17 (GH17) $\beta$-1,3-glucanases (PF00332), six PR-3 GH19 family chitinases (PF00182), two PR-4 hevin-like barwin domain-containing proteins (PF00967), eight PR-5 thaumatin/osmotin-like proteins (PF00314), and 21 PR-6 protease inhibitors. The remaining significantly regulated genes included 11 PR-7 subtilisin-like proteinases (IPR023828), 34 PR-9 peroxidases (IPR002016), six PR-10 Bet v 1 allergen (PF00407) ribonuclease-like proteins, four PR-11 GH18 family chitinases (PF00704), five PR-12 cysteine- rich plant defensins (PF00304), 13 PR-14 lipid-transfer proteins (IPR000528), 13 PR15/16 germin/germin-like proteins (GLPs) with oxalate oxidase activity (PF00190), and three PR-17 basic secretory proteins (BSPs) (PF04450). No differential or constitutive gene expression was found for any of the 45 PR-13 cysteinerich thionin genes (PF00321) present in the barley reference genome.

Differential gene expression of most PR groups between 2 and 7 dpi comprised both induced and suppressed genes. All genes in the PR-1 cysteine-rich secretory CAP domaincontaining proteins and PR-11 chitinases were induced during $P$. teres f. teres infection, while groups in which a majority (greater than $80 \%$ ) of genes were induced included PR-5 thaumatin/osmotin like proteins, PR-6 protease inhibitors, PR-10 Bet $\mathrm{v} 1$ allergen ribonuclease-like proteins and PR-15/16 GLPs. The majority of PR-14 lipid-transfer protein genes were suppressed.

Transport-related and detoxification defense mechanisms.

Numerous barley transport related genes were significantly differentially expressed during $P$. teres $\mathrm{f}$. teres infection. These included calmodulin and calcium transporting ATPase proteins, glutathione transferases, cytochrome P450s, ATP-binding (ABC) transporter/multidrug resistance-associated protein families, and UDP glucosyl/glucoronyl transferases (Table 2).

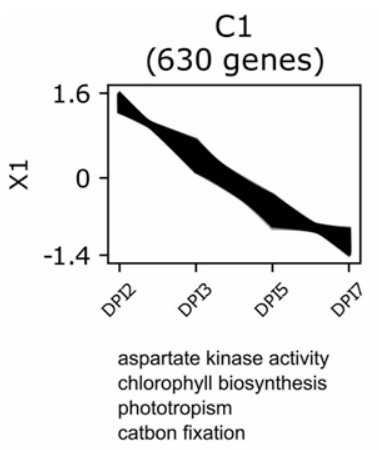

C6

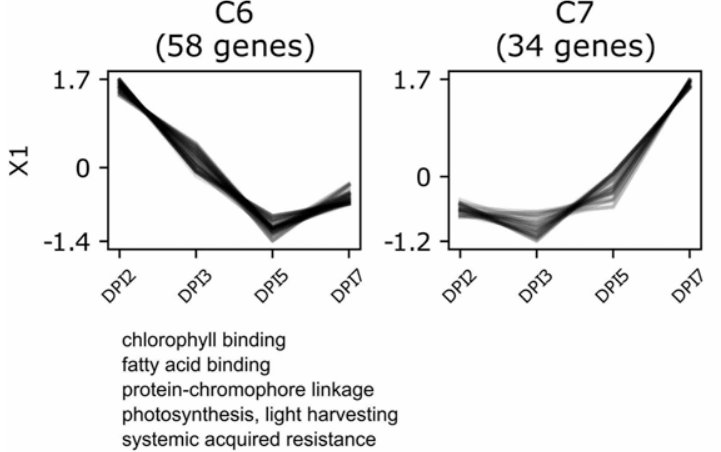

C11 (609 genes)

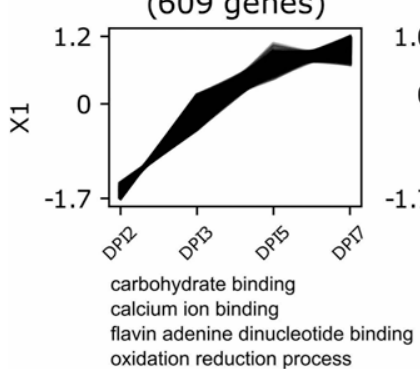

$\mathrm{C} 2$

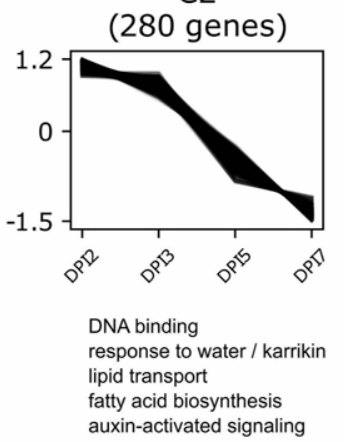

C7

C12 (187 genes)

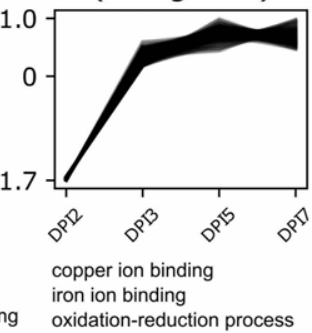

C3

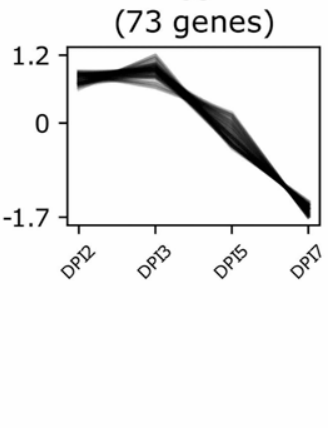

C8

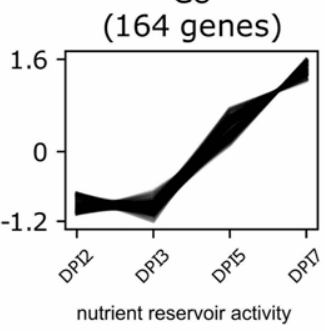

C4

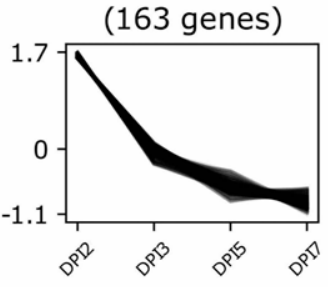

chlorophyll binding

photosynthesis, light harvesting protein-chromophore linkage sesquiterpenoid biosynthesis

C9 (311 genes)

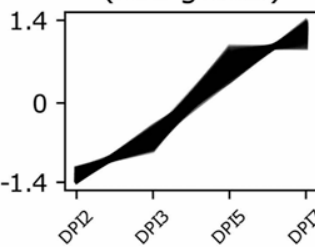

catechol oxidase activity serine-type endopeptidase inhibitor activity

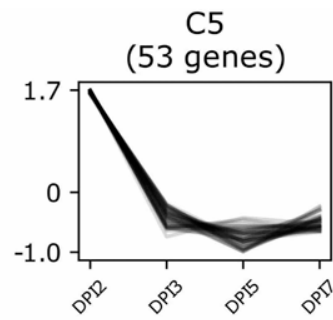

chlorophyll binding

photosynthesis, light harvesting protein-chromophore linkage GDP-manose transmembrane transport

C10

(93 genes)

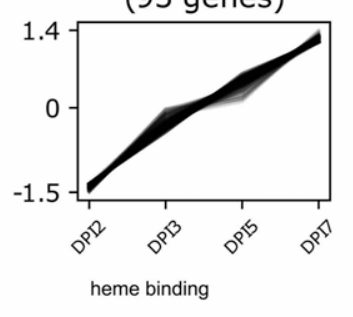

Fig. 6. Barley cultivar Baudin gene expression profiles during Pyrenophora teres f. teres isolate W1-1 infection from 2 to 7 days postinoculation. Expression profile groups $\mathrm{C} 1-\mathrm{C} 13$ are depicted from top to bottom. 


\section{Biosynthetic and signaling pathway activation.}

Key enzymes for phytohormone signaling pathways involving salicylic acid (SA), jasmonic acid (JA), and ethylene (ET) were also explored (Table 3). For the JA biosynthetic pathway, lipoxygenase (LOX), allene oxide cyclase, allene oxide synthase, 12oxophytodienoate reductase, and acyl-CoA oxidase were induced or constitutively expressed. Homologs of two key enzymes in the ET biosynthetic pathway, 1-aminocyclopropane1-carboxylic acid (ACC) synthase (HORVU4Hr1G009800) and ACC oxidase (HORVU5Hr1G067530) were suppressed or constitutively expressed (HORVU6Hr1G079640 and HORVU6Hr1G079600). SA enzymes for isochorismate were constitutively expressed during infection. Gene activation in secondary metabolite pathways related to plant defense were found

Table 2. Overview of barley defense-related genes induced during net form net blotch (NFNB) infection

\begin{tabular}{|c|c|c|c|c|c|c|c|}
\hline Defense type & Defense category & $\begin{array}{c}\mathrm{DE} \\
\text { gene }^{\mathrm{a}}\end{array}$ & Induced & Suppressed & Source & Domain type/description & $\begin{array}{c}\text { Apoplast } \\
\text { protein } \\
\text { expression }\end{array}$ \\
\hline $\begin{array}{l}\text { Transcription } \\
\text { activation }\end{array}$ & Transcription factor & 173 & 83 & 90 & GO:0006355 & $\begin{array}{l}\text { SANT/Myb domain/zinc } \\
\text { finger C2H2-type/WRKY } \\
\text { domain }\end{array}$ & - \\
\hline \multirow{4}{*}{$\begin{array}{l}\text { Pathogen } \\
\text { sensing and } \\
\text { signaling }\end{array}$} & Receptor-like protein kinase & 226 & 134 & 92 & GO:0004672 & Protein kinase activity & - \\
\hline & Disease resistance proteins & 24 & 11 & 13 & IPR002182 & NB-ARC & - \\
\hline & & 69 & 35 & 34 & IPR001611 & Leucine-rich repeat & - \\
\hline & Mlo-like & 2 & 0 & 2 & IPR004326 & Mlo-related protein & - \\
\hline \multirow{18}{*}{$\begin{array}{l}\text { Pathogenesis } \\
\text { Related (PR) } \\
\text { Proteins }\end{array}$} & PR-1 cysteine-rich & 7 & 7 & 0 & PF00188 & CAP domain & Up \\
\hline & & & & & & $\begin{array}{l}\text { HvPR1a_CAA52893 and } \\
\text { HvPR1b_CAA52894 }\end{array}$ & \\
\hline & PR-2 endo-1,3- $\beta$-glucanase & 16 & 6 & 10 & PF00332 & GH17 Glyco_hydro_17 & Up and down \\
\hline & $\begin{array}{l}\text { PR-3 chitinase Class } 1, \text { II, } \\
\text { IV, V11 }\end{array}$ & 6 & 4 & 2 & PF00182 & $\begin{array}{l}\text { GH19 Glyco_hydro_19 } \\
\text { Class } 1 \text {, II and IV }\end{array}$ & $\mathrm{Up}$ \\
\hline & PR-4 Barwin domain & 2 & 1 & 1 & PF00967 & Hevin-like & $\mathrm{Up}$ \\
\hline & PR-5 thaumatin-like & 8 & 7 & 1 & PF00314 & Osmotin & $\mathrm{Up}$ \\
\hline & PR-6 protease inhibitor & 21 & 17 & 4 & $\begin{array}{l}\text { PF00079 } \\
\text { PF00228 } \\
\text { PF00280 }\end{array}$ & $\begin{array}{l}\text { Serpin, Bowman-Birk type } \\
\text { trypsin, Trypsin/ } \alpha \text {-amylase } \\
\text { inhibitor (BASI), Kunitz } \\
\text { type, Chymotrypsin/ } \\
\text { subtilisin, Potato inhibitor I } \\
\text { family }\end{array}$ & Up \\
\hline & PR-7 subtilisin-like proteinase & 11 & 5 & 6 & IPR041469 & Endoproteinase & - \\
\hline & PR-8 chitinase class III & 0 & 0 & 0 & PF00704 & & None \\
\hline & PR-9 peroxidase & 34 & 14 & 20 & IPR002016 & Haem peroxidase III & Up \\
\hline & PR-10 Bet v 1 allergen & 6 & 5 & 1 & PF00407 & Ribonuclease-like proteins & - \\
\hline & PR-11 chitinase class V & 4 & 4 & 0 & & $\begin{array}{l}\text { GH18 Glyco_hydro_18 } \\
\text { triosephosphate isomerase } \\
\text { (TIM) barrel }(\beta / \alpha) \\
8 \text { domain }\end{array}$ & - \\
\hline & $\begin{array}{l}\text { PR-12 plant defensin (cysteine- } \\
\text { rich) }\end{array}$ & 5 & 3 & 2 & PF00304 & $\begin{array}{l}\text { Gamma-thionin/defensin2/ } \\
\text { toxin } 3 \text { IPR008176 } \\
\text { (gamma-hordothionins) }\end{array}$ & - \\
\hline & PR-13 thionin (cysteine-rich) & 0 & 0 & 0 & PF00321 & & None \\
\hline & PR-14 lipid-transfer protein & 13 & 2 & 11 & PF00234 & $\begin{array}{l}\text { Nonspecific lipid-transfer } \\
\text { protein/ } \alpha \text {-amylase/ } \\
\text { trypsin inhibitor } \\
\text { (HORVU6Hr1G066330) }\end{array}$ & Up \\
\hline & PR-15 oxalate oxidase (germins) & 9 & 9 & 0 & PF00190 & $\begin{array}{l}\text { Monocupin (germin) proteins } \\
\text { Cupin-Germin, manganese } \\
\text { binding site IPR019780 }\end{array}$ & None \\
\hline & $\begin{array}{l}\text { PR-16 oxalate oxidase-like } \\
\quad \text { (germin-like proteins [GLPs]) }\end{array}$ & 4 & 3 & 1 & & $\begin{array}{c}\text { GLPs/oxalate oxidase-like } \\
\text { nonmanganese binding }\end{array}$ & Up \\
\hline & $\begin{array}{l}\text { PR-17 basic secretory } \\
\text { proteins (BSPs) }\end{array}$ & 3 & 1 & 2 & $\begin{array}{l}\text { PF04450 } \\
\text { IPR007541 }\end{array}$ & $\begin{array}{l}\text { Peptidase of plants-BSPs } \\
\text { (HvPR17a and HvPR-17b) }\end{array}$ & \\
\hline \multirow{5}{*}{$\begin{array}{l}\text { Transport- } \\
\text { related }\end{array}$} & Transporter & 159 & 76 & 83 & GO:0055085 & Transmembrane transport & - \\
\hline & ABC-transporter & 25 & 12 & 13 & IPR003439 & & - \\
\hline & Amino acid transporter & 21 & 10 & 11 & IPR013057 & & - \\
\hline & Aquaporins & 10 & 2 & 8 & IPR034294 & & - \\
\hline & Sugar transporter & 24 & 10 & 9 & IPR005828 & & - \\
\hline \multirow[t]{4}{*}{ Other } & Detoxification (MATE) & 10 & 5 & 5 & PF01554 & & - \\
\hline & Glutathione $S$-transferase & 33 & 26 & 7 & $\begin{array}{l}\text { PF02798 } \\
\text { PF13417 }\end{array}$ & & - \\
\hline & Cytochrome P450 & 101 & 60 & 41 & PF00067 & & - \\
\hline & $\begin{array}{l}\text { UDP-glucuronosyl/ } \\
\text { UDP-glucosyltransferase }\end{array}$ & 47 & 29 & 18 & IPR002213 & & - \\
\hline $\begin{array}{l}\text { Chloroplast- } \\
\text { related }\end{array}$ & & 127 & 16 & 111 & GO:0009507 & & - \\
\hline
\end{tabular}

${ }^{a}$ Significantly differentially expressed (DE).

${ }^{\mathrm{b}}$ Apoplast proteins identified during barley NFNB (Hassett et al. 2020). 
for the terpenoid biosynthetic pathway, with the key terpenoid enzyme, 1-deoxy-D-xylulose-5-phosphate synthase (DXPS), found to be significantly regulated during infection. Tryptophan decarboxylase enzymes were constitutively expressed.

In the core phenylpropanoid pathway, phenylalanine ammonia lyase was not differentially regulated but was constitutively expressed, while hydroxycinnamoyl-CoA:shikimate/quinate hydroxycinnamoyltransferase and 4-coumarate-CoA ligase enzymes were induced. In flavonoid biosynthesis, the chalcone synthase enzyme was constitutively expressed and chalcone isomerase was suppressed. Hordatine enzymes arginine decarboxylase and agmatine coumaroyltransferase were highly and

Table 3. Barley gene expression during net form net blotch (NFNB) related to hormone signaling and secondary metabolite biosynthesis

\begin{tabular}{|c|c|c|c|c|c|c|}
\hline Biosynthetic pathway & Gene description & DE gene $^{a}$ & Induced & Suppressed & Source & Expressed $^{\mathbf{b}}$ \\
\hline \multirow[t]{4}{*}{$\begin{array}{l}\text { Ethylene basic } \\
\text { secretory (BS) }\end{array}$} & $\begin{array}{l}\text { 1-Aminocyclopropane-1-carboxylic acid } \\
\text { (ACC) synthase }\end{array}$ & 1 & 0 & 1 & HORVU4Hr1G009800 & \\
\hline & ACC oxidase & 1 & 0 & 1 & HORVU5Hr1G067530 & Yes \\
\hline & & & & & HORVU6Hr1G079640 & Yes \\
\hline & & & & & HORVU6Hr1G079600 & \\
\hline \multirow[t]{13}{*}{ Jasmonate BS } & Lipoxygenase & 6 & 3 & 3 & HORVU5Hr1G001180 & \\
\hline & & & & & HORVU4Hr1G076570 & \\
\hline & & & & & HORVU2Hr1G115980 & \\
\hline & & & & & HORVU7Hr1G050680 & \\
\hline & & & & & HORVU7Hr1G050660 & \\
\hline & & & & & HORVU2Hr1G115960 & \\
\hline & Allene oxide synthase & 0 & 0 & 0 & HORVU5Hr1G098090 & Yes \\
\hline & Allene oxide cyclase & 1 & 1 & 0 & HORVU6Hr1G081000 & \\
\hline & 12-Oxophytodienoate reductase & 0 & 0 & 0 & HORVU7Hr1G095960 & Yes \\
\hline & Acyl-CoA oxidase & 3 & 3 & 0 & HORVU1Hr1G013820 & \\
\hline & & & & & HORVU2Hr1G018720 & \\
\hline & & & & & HORVU7Hr1G029110 & \\
\hline & 3-Ketoacyl-CoA thiolase & & & & & \\
\hline \multirow[t]{8}{*}{ Salicylic acid (SA) } & Isochorismate synthase & 0 & 0 & 0 & HORVU5Hr1G057050 & Yes \\
\hline & & & & & HORVU1Hr1G022060 & \\
\hline & & & & & HORVU2Hr1G038120 & \\
\hline & & & & & HORVU2Hr1G038140 & \\
\hline & & & & & HORVU2Hr1G089440 & \\
\hline & & & & & HORVU2Hr1G089540 & \\
\hline & & & & & HORVU6Hr1G058820 & \\
\hline & & & & & HORVU6Hr1G058840 & \\
\hline Terpenoid & 1-Deoxy-D-xylulose-5-phosphate synthase & 3 & 2 & 1 & GO:0008661 & \\
\hline \multirow[t]{3}{*}{ Tryptophan } & Tryptophan decarboxylase & 0 & 0 & 0 & HORVU2Hr1G114390 & Yes \\
\hline & & & & & HORVU2Hr1G114450 & \\
\hline & & & & & HORVU2Hr1G114440 & \\
\hline \multirow[t]{14}{*}{ Phenylpropanoid } & Phenylalanine ammonia-lyase & 0 & 0 & 0 & HORVU0Hr1G016330 & Yes \\
\hline & & & & & HORVU1Hr1G022060 & \\
\hline & & & & & HORVU2Hr1G038120 & \\
\hline & & & & & HORVU2Hr1G038140 & \\
\hline & & & & & HORVU2Hr1G089440 & \\
\hline & & & & & HORVU2Hr1G089540 & \\
\hline & & & & & HORVU6Hr1G058820 & \\
\hline & & & & & HORVU6Hr1G058840 & \\
\hline & Cinnamic acid 4-hydroxylase & 0 & 0 & 0 & - & - \\
\hline & 4-Coumarate-CoA ligase & 2 & 1 & 1 & HORVU0Hr1G018190 & Yes \\
\hline & & & & & HORVU7Hr1G111130 & \\
\hline & & & & & HORVU6Hr1G030390 & \\
\hline & & & & & HORVU0Hr1G002720 & \\
\hline & $\begin{array}{l}\text { Hydroxycinnamoyl-CoA:shikimate/quinate } \\
\text { hydroxycinnamoyltransferase }\end{array}$ & 2 & 1 & 1 & GO:0050734 & \\
\hline \multirow[t]{4}{*}{ Flavonoid } & Chalcone synthase & 0 & 0 & 0 & HORVU2Hr1G116390 & Yes \\
\hline & Chalcone and stilbene synthases & 8 & 5 & 3 & IPR001099 & \\
\hline & Chalcone isomerase & 2 & 0 & 2 & HORVU5Hr1G046480 & \\
\hline & & & & & HORVU5Hr1G112670 & \\
\hline \multirow[t]{7}{*}{ Hordatines } & Agmatine coumaroyltransferase HvACT & 0 & 0 & 0 & HORVU2Hr1G109430 & Yes \\
\hline & & & & & HORVU2Hr1G109590 & \\
\hline & Arginine decarboxylase & 0 & 0 & 0 & HORVU7Hr1G012530 & Yes \\
\hline & & & & & HORVU7Hr1G012560 & \\
\hline & & & & & HORVU1Hr1G002090 & \\
\hline & & & & & HORVU2Hr1G010000 & \\
\hline & Peroxidase (HvPrx7) & 0 & 0 & 0 & HORVU2Hr1G124930 & Yes \\
\hline \multirow[t]{3}{*}{ Lignin BS } & $\begin{array}{l}\text { COMT, CCR, F5H, (hydroxy)cinnamyl } \\
\text { alcohol dehydrogenase (caffeoyl-CoAO } \\
\text { methyltransferase (CCoAOMT) }\end{array}$ & & & & & \\
\hline & CAD & 2 & 0 & 2 & GO:0045551 & \\
\hline & CCoAOMT & 1 & 0 & 1 & HORVU7Hr1G049070 & \\
\hline Lignin catabolism & Laccase & 9 & 6 & 3 & GO:0046274 & \\
\hline
\end{tabular}

${ }^{a}$ Significantly differentially expressed (DE) genes during NFNB infection.

${ }^{\mathrm{b}}$ Constitutively expressed. 
constitutively expressed at all timepoints. However, key enzymes in a lignin-specific pathway, (hydroxy)cinnamyl alcohol dehydrogenase, and caffeoyl-CoAO methyltransferase were significantly suppressed during infection by NFNB. In contrast to lignin biosynthesis, catabolic laccase enzymes were found to be significantly induced.

\section{DISCUSSION}

Metabolic changes promoting disease during NFNB.

$P$. teres f. teres gene expression during infection of the NFNB susceptible cultivar Baudin was characterized by induced plant cell-wall macromolecule catabolic processes that plateaued during the necrotrophic phase, indicating sustained expression. This involved glucanase and peptidase activity and carbohydrate metabolism, which would thereby allow the rapid assimilation of host nutrients, essential for successful pathogenesis. In barley, concomitant plant cell death from induced HR, rather than restricting nutrient availability at the site of infection (Mur et al. 2017), is advantageous to a necrotrophic pathogen. $P$. teres f. teres does not attempt to evade high levels of ROS but suppresses its response to oxidative stress and metabolism of reactive nitrogen species, thereby promoting further cell death.

An observed increased barley response to nitrogen levels could be an attempt to reallocate nutrients to defense responses or away from the site of attempted infection (Mur et al. 2017). Ammonium levels can compromise defense and be a source of nutrition for the pathogen, while nitrate levels can augment defense signals and HR (Mur et al. 2017). In contrast, during infection, $P$. teres $\mathrm{f}$. teres appears to suppress ammonium transmembrane transport, nitrate assimilation, nitrogen cycle, and reactive nitrogen species metabolic processes.

Barley reduction in phototropism and photosynthesis activities and processes also implies a possible redirection of energy to maintain host HR and the ultimate collapse of phototropic mechanisms (Pandelova et al. 2009). An incompatibility between host growth (including the need for photosynthetic functions) and defense processes exists, in which growth is suppressed during high levels of ROS (Neuser et al. 2019). Together these observed host-pathogen interactions appear to contribute to host cell death and NFNB disease development on cv. Baudin.

Key genes in plant defense hormone signaling pathways for the ET, SA, and phenylpropanoid biosynthesis pathways were not induced in cv. Baudin during infection, while enzymes in the jasmonate (LOX) and terpenoid (DXPS) biosynthetic pathways showed no overall induction, being both induced and suppressed.

\section{Host defense-related responses to NFNB.}

Plant resistance genes are at the interface of pathogen recognition and activation of defense responses. Plant innate immunity-based intracellular receptors (ETI), such as disease resistance proteins, recognize specific pathogen effectors (Czernic et al. 1999; Hajouj et al. 2000; Heese et al. 2007; Macho and Zipfel 2014; Ngou et al. 2020; Postel et al. 2010). Over half the putative resistance genes annotated as LRR-containing or NB-ARC domain- (van Ooijen et al. 2008) containing proteins $(56 \%$ or 180 genes) were found to be induced. Plant resistance genes activate a range of response, including a hypersensitive reaction (localized cell death), with a single resistance gene usually mediating the plant response. Since a HR would appear to favor a necrotroph, this global induction of resistance genes is highly significant.

Plant immunity based on extracellular PTI such as $R L K$ s and receptor-like proteins are initiated on pathogen recognition (Czernic et al. 1999; Hajouj et al. 2000; Heese et al. 2007; Macho and Zipfel 2014; Ngou et al. 2020; Postel et al. 2010). In this study, a large number of $R L K \mathrm{~s}$ were found to be highly induced and, although ETI requires the potentiation of PTI to provide effective resistance to pathogens (Ngou et al. 2020), further investigation is required to determine if these genes are activated by $P$. teres $\mathrm{f}$. teres infection or are part of a general stress response (Hong et al. 1997).

Components of the plant innate immune system and systemic acquired resistance, PR proteins are a diverse group of molecules induced by phytopathogens. PR proteins provide enhanced resistance against both biotic and abiotic stresses and are considered potential candidates toward the development of stress-tolerant crops (Ali et al. 2018). Furthermore, the expression of PR proteins individually or in combination may determine the type of defense response interaction against specific pathogens. Two conspicuous PR protein groups, thionin and nonspecific lipidtransfer protein (nsLTP), showed either complete absence of gene expression or gene expression in the majority was suppressed, respectively. Thionins are small cysteine-rich proteins that increase hyphal membrane permeability and result in cellular lysis, while nsLTPs bind and transfer membrane phospholipids involved in plant defense response (Laluk and Mengiste 2010). Thionin and nsLTP have been previously reported to function synergistically to inhibit fungal growth (Molina et al. 1993), and, in the susceptible interaction, transcription of these two host defense groups appear to be compromised. Even though thionins are highly abundant antifungal polypeptides found in the cell walls and vacuoles of barley leaf cells (Apel et al. 1990; Bohlmann and Apel 1991), apoplastic thionin was also absent during NFNB infection (Hassett et al. 2020). A complex polymorphic multigene family (Bohlmann et al. 1988; Bunge et al. 1992), there are 45 thionins annotated in the reference genome of $\mathrm{cv}$. Morex.

In general, the PR protein groups induced in the susceptible interaction mostly support host cell death, a favorable condition for necrotrophy, and those groups involved in pathogen inhibition appeared to be suppressed. Barley transcription activation was also highly regulated during NFNB, with a large proportion of transcription factors either induced $(47 \%)$ or suppressed $(53 \%)$.

\section{Regulation of putative $\boldsymbol{P}$. teres $\mathrm{f}$. teres effector protein and biosynthetic gene clusters during NFNB.}

The genome of $P$. teres $\mathrm{f}$. teres encodes hundreds of predicted phytotoxic effector-like proteins, of which a large proportion were highly expressed. All but a few had significant changes in expression at the stage when $P$. teres f. teres transition to the necrotrophic phase. In particular, those predicted effector genes with a C6 profile with an early increase in expression between 2 and 3 dpi may potentially represent "gene-for-gene" effector candidates (Liu et al. 2015). Induction of syncytium formation in susceptible barley, may also contribute to cell-to-cell spread of $P$. teres $\mathrm{f}$. teres secreted toxins and glycoproteins during the necrotrophic phase.

Predicted effectors usually lack a conserved protein domain and, of those significantly induced, one predicted effector was annotated as a DJ-1 (damage protection) protein and is located in a known NFNB QTL (QTL7, conferring virulence in cv. Beecher) (Martin et al. 2020). Interestingly, in Arabidopsis the AtDJ-la gene interacts with superoxide dismutase (SOD1) and glutathione peroxidase 2 (GPX2) to confer stress protection $(\mathrm{Xu}$ et al. 2010).

Among the biosynthetic gene clusters regulated during NFNB, the suppression of fatty acid biosynthesis and a predicted biosynthetic gene cluster at the critical pathogen transition phase to necrotrophy may indicate that certain metabolic compounds are only required during early infection and that the pathogen 
may be redirecting energy to more important processes during necrotrophy.

\section{Conclusions.}

This is the first RNA-seq analysis providing a time series overview of gene expression in both host and pathogen during barley NFNB disease in a susceptible cultivar. Key responses included the large-scale induction of LRR resistance genes in the host and plant cell wall-degrading enzymes in $P$. teres f. teres during infection. Opposing interactions were observed, which included induced oxidoreductase catalytic activities in barley, which was met with a direct downregulation in $P$. teres f. teres. $P$. teres f. teres hydrolase activities showed a consistent increase in expression during the necrotrophic phase, and a number of biosynthetic gene clusters appeared to respond to the change from asymptomatic to necrotrophic interaction. The significance of the complete absence of thionin expression in a NFNB susceptible cultivar and whether this is a result of an ineffective susceptible host response remains to be seen. Furthermore, this study provides candidate genes for functional characterization of the contributions of $P$. teres $\mathrm{f}$. teres biosynthetic gene clusters and predicted effectors in $P$. teres $\mathrm{f}$. teres virulence.

\section{MATERIALS AND METHODS}

\section{Reference genomes for Pyrenophora teres f. teres and barley.}

The genome assembly for $P$. teres f. teres isolate W1-1 (Syme et al. 2018) was downloaded from the National Center for Biotechnology Information GenBank database (Bioproject PREB18107, accession GCA 900232045.1) and the International Barley Sequencing Consortium barley genome version 2.43 (Beier et al. 2017) was downloaded from EnsemblPlant (Howe et al. 2020). The two genomes were used as the reference genomes for $P$. teres $\mathrm{f}$. teres and barley throughout this analysis.

\section{Inoculation of barley leaves \\ with $P$. teres f. teres and tissue sampling.}

Second leaves from 2-week-old barley seedlings (cv. Baudin) were cut into $5-\mathrm{cm}$ sections and were embedded in $12-\mathrm{cm}^{2}$ square Petri dishes containing $50 \mathrm{mg}$ of benzimidazole agar per liter. Aliquots $(5 \mu \mathrm{l})$ of $P$. teres $\mathrm{f}$. teres W1-1 conidia $(0.93 \times$ $10^{3}$ conidia per milliliter of $0.05 \%$ Tween-20) were spotted onto the leaves. Three replicate plates per timepoint were used and the number of replicate leaves and spots per leaf per plate were scaled in accordance with the amount of infected tissue available for RNA extraction (e.g., for samples taken at 2 dpi, 12 leaves with three droplets of conidia per leaf were used and at $7 \mathrm{dpi}$, eight leaves with one spot). Plates were sealed with parafilm, were placed in a controlled environment chamber with a 12$\mathrm{h}$ photoperiod, and were maintained at $22^{\circ} \mathrm{C}$. Diseased lesions were excised from leaves at 2, 3, 5, and $7 \mathrm{dpi}$, were snap-frozen in liquid nitrogen, and were then stored at $-80^{\circ} \mathrm{C}$ prior to RNA extraction.

\section{RNA extraction and sequencing.}

RNA was extracted using a PureLink RNA mini kit extraction kit (Invitrogen, Carlsbad, CA, U.S.A.) in accordance with manufacturer instructions. RNA concentration was measured using a NanoDrop 2000 spectrophotometer (ThermoFisher Scientific, Wilmington, DE, U.S.A.), and $20 \mu \mathrm{g}$ of each RNA sample was DNAse treated (DNA-free DNA removal kit, Invitrogen, Carlsbad, CA, U.S.A.), before verifying RNA integrity on a $1 \%$ agarose gel. Isolated RNA was sequenced by the Ramaciotti Centre (UNSW, Sydney, Australia), using TruSeq stranded mRNA on a NextSeq500 instrument. Paired-end reads of $2 \times 150 \mathrm{bp}$, yielded over $860 \mathrm{Gbp}$ with an average Q30 of $81 \%$. The sequence read data has been deposited in the European Nucleotide Archive under study accession number PRJEB34186.

RNA sequence analysis and expression profiling.

RNA-seq reads were quality checked with FastQC (Andrews 2011) and were trimmed with a Phred score $\geq 30$ with Trimmomatic v0.33 (Bolger et al. 2014), with HEADCROP:12, ILLUMINACLIP:TruSeq-PE.fa:2:30:5, LEADING:10, TRAILING:10, SLIDINGWINDOW:4:25 and MINLEN:50 parameters. Quality trimmed reads were aligned to the reference genomes using the RNA-seq aligner Star version 2.7.0e (Dobin et al. 2013) with quantMode equal to GeneCounts. Gene expression counts were calculated and guided by barley and P. teres f. teres reference gene annotations. Normalization and gene-dispersion estimates was performed using R v3.3.3 package Deseq2 version 1.12.4 (Love et al. 2014). Significant differential gene expression between the different timepoints was set at $\geq 2$-fold change and a Benjamini-Hochberg adjusted $P$ value (false discovery rate) $\leq 0.05$ (Benjamini and Hochberg 1995), based on timepoint contrasts. Gene plots were constructed using R v3.5.1 with chromPlot v1.10.0, GenomicFeatures v1.34.8, tidyverse v1.3.0, ggpubr v0.2.4, and ggplot2 v3.2.1 libraries.

Significant normalized and pairwise differentially expressed genes were clustered using the optimized consensus clustering tool Clust v1.10.8 (Abu-Jamous and Kelly 2018), with a tightness of cluster ( $\delta$-cluster) set to 2 to reveal the gene expression regulation patterns over the course of infection ( 2 to $7 \mathrm{dpi}$ ).

\section{$P$. teres f. teres W1-1 effector and biosynthetic gene clusters predictions.}

The W1-1 proteins were searched for signal peptides using SignalP version 5.0b (Petersen et al. 2011) (-format short -gff3 -mature -org euk). Those identified with signal peptides were then searched for predicted effectors using EffectorP version 2.0 (Sperschneider et al. 2018).

Previously predicted $P$. teres f. teres W1-1 biosynthetic gene clusters were used in this study (Moolhuijzen et al. 2020).

\section{Functional analysis.}

Functional enrichment for differentially expressed genes was determined using $\mathrm{R}$ version 3.5.1, topGO version 2.34.0, and Rgraphviz version 2.26.0. The set of significantly expressed gene ontologies $(\mathrm{GO})$ were compared with the ontologies for the genomes total number of genes (population background) to determine enrichment, using classic Fisher exact test. GO terms with $P$ values $\leq 0.05$ were selected as enriched.

Bar plots were constructed using R v3.5.1, ggpubr v0.2.4, and ggplot2 v3.2.1 libraries.

\section{ACKNOWLEDGMENTS}

This work used computational resources provided by the Australian Government through the Pawsey Supercomputing Centre under the National Computational Merit Allocation Scheme (NCMAS). This research also used the Nectar Research Cloud and the Pawsey Nimbus cloud services, a collaborative Australian research platform supported by the National Collaborative Research Infrastructure Strategy (NCRIS). We would also like to acknowledge V. Piscetek for his assistance with the experiment set up and RNA extraction.

\section{LITERATURE CITED}

Abu-Jamous, B., and Kelly, S. 2018. Clust: Automatic extraction of optimal co-expressed gene clusters from gene expression data. Genome Biol. 19:172. 
Ali, S., Ganai, B. A., Kamili, A. N., Bhat, A. A., Mir, Z. A., Bhat, J. A., Tyagi, A., Islam, S. T., Mushtaq, M., Yadav, P., Rawat, S., and Grover, A. 2018. Pathogenesis-related proteins and peptides as promising tools for engineering plants with multiple stress tolerance. Microbiol. Res. 212-213:29-37.

Andrews, S. 2011. FastQC. Babraham Institute, Cambridge. Published online. https://www.bioinformatics.babraham.ac.uk/projects/fastqc/

Apel, K., Bohlmann, H., and Reimann-Philipp, U. 1990. Leaf thionins, a novel class of putative defence factors. Physiol. Plant. 80:315-321.

Beier, S., Himmelbach, A., Colmsee, C., Zhang, X. Q., Barrero, R. A., Zhang, Q., Li, L., Bayer, M., Bolser, D., Taudien, S., Groth, M., Felder, M., Hastie, A., Simková, H., Staňková, H., Vrána, J., Chan, S., Muñoz-Amatriaín, M., Ounit, R., Wanamaker, S., Schmutzer, T., Aliyeva-Schnorr, L., Grasso, S., Tanskanen, J., Sampath, D., Heavens, D., Cao, S., Chapman, B., Dai, F., Han, Y., Li, H., Li, X., Lin, C., McCooke, J. K., Tan, C., Wang, S., Yin, S., Zhou, G., Poland, J. A., Bellgard, M. I., Houben, A., Doležel, J., Ayling, S., Lonardi, S., Langridge, P., Muehlbauer, G. J., Kersey, P., Clark, M. D., Caccamo, M., Schulman, A. H., Platzer, M., Close, T. J., Hansson, M., Zhang, G., Braumann, I., Li, C., Waugh, R., Scholz, U., Stein, N., and Mascher, M. 2017. Construction of a map-based reference genome sequence for barley, Hordeum vulgare L. Sci. Data 4:170044.

Benjamini, Y., and Hochberg, Y. 1995. Controlling the false discovery rate-A practical and powerful approach to multiple testing. J. R. Stat. Soc. B 57:289-300.

Blake, V. C., Woodhouse, M. R., Lazo, G. R., Odell, S. G., Wight, C. P., Tinker, N. A., Wang, Y., Gu, Y. Q., Birkett, C. L., Jannink, J. L., Matthews, D. E., Hane, D. L., Michel, S. L., Yao, E., and Sen, T. Z. 2019. GrainGenes: Centralized small grain resources and digital platform for geneticists and breeders. Database (Oxford) 2019:baz065.

Bohlmann, H., and Apel, K. 1991. Thionins. Annu. Rev. Plant Physiol. Plant Mol. Biol. 42:227-240.

Bohlmann, H., Clausen, S., Behnke, S., Giese, H., Hiller, C., ReimannPhilipp, U., Schrader, G., Barkholt, V., and Apel, K. 1988. Leafspecific thionins of barley-a novel class of cell wall proteins toxic to plant-pathogenic fungi and possibly involved in the defence mechanism of plants. EMBO J. 7:1559-1565.

Bolger, A. M., Lohse, M., and Usadel, B. 2014. Trimmomatic: A flexible trimmer for Illumina sequence data. Bioinformatics 30:2114-2120.

Bunge, S., Wolters, J., and Apel, K. 1992. A comparison of leaf thionin sequences of barley cultivars and wild barley species. Mol. Gen. Genet. 231:460-468.

Czernic, P., Visser, B., Sun, W., Savouré, A., Deslandes, L., Marco, Y., Van Montagu, M., and Verbruggen, N. 1999. Characterization of an Arabidopsis thaliana receptor-like protein kinase gene activated by oxidative stress and pathogen attack. Plant J. 18:321-327.

Dobin, A., Davis, C. A., Schlesinger, F., Drenkow, J., Zaleski, C., Jha, S., Batut, P., Chaisson, M., and Gingeras, T. R. 2013. STAR: Ultrafast universal RNA-seq aligner. Bioinformatics 29:15-21.

Ellwood, S. R., Piscetek, V., Mair, W. J., Lawrence, J. A., Lopez-Ruiz, F. J., and Rawlinson, C. 2019. Genetic variation of Pyrenophora teres f. teres isolates in Western Australia and emergence of a Cyp51A fungicide resistance mutation. Plant Pathol. 68:135-142.

Faris, J. D., and Friesen, T. L. 2020. Plant genes hijacked by necrotrophic fungal pathogens. Curr. Opin. Plant Biol. 56:74-80.

Hajouj, T., Michelis, R., and Gepstein, S. 2000. Cloning and characterization of a receptor-like protein kinase gene associated with senescence. Plant Physiol. 124:1305-1314.

Hassett, K., Ellwood, S. R., Zulak, K. G., and Muria-Gonzalez, M. J. 2020. Analysis of apoplastic proteins expressed during net form net blotch of barley. J. Plant Dis. Prot. 127:683-694.

Heese, A., Hann, D. R., Gimenez-Ibanez, S., Jones, A. M., He, K., Li, J., Schroeder, J. I., Peck, S. C., and Rathjen, J. P. 2007. The receptor-like kinase SERK3/BAK1 is a central regulator of innate immunity in plants. Proc. Natl. Acad. Sci. U.S.A. 104:12217-12222.

Hong, S. W., Jon, J. H., Kwak, J. M., and Nam, H. G. 1997. Identification of a receptor-like protein kinase gene rapidly induced by abscisic acid, dehydration, high salt, and cold treatments in Arabidopsis thaliana. Plant Physiol. 113:1203-1212.

Howe, K. L., Contreras-Moreira, B., De Silva, N., Maslen, G., Akanni, W., Allen, J., Alvarez-Jarreta, J., Barba, M., Bolser, D. M., Cambell, L., Carbajo, M., Chakiachvili, M., Christensen, M., Cummins, C., Cuzick, A., Davis, P., Fexova, S., Gall, A., George, N., Gil, L., Gupta, P., Hammond-Kosack, K. E., Haskell, E., Hunt, S. E., Jaiswal, P., Janacek, S. H., Kersey, P. J., Langridge, N., Maheswari, U., Maurel, T., McDowall, M. D., Moore, B., Muffato, M., Naamati, G., Naithani, S., Olson, A., Papatheodorou, I., Patricio, M., Paulini, M., Pedro, H., Perry, E., Preece, J., Rosello, M., Russell, M., Sitnik, V., Staines, D. M.,
Stein, J., Tello-Ruiz, M. K., Trevanion, S. J., Urban, M., Wei, S., Ware, D., Williams, G., Yates, A. D., and Flicek, P. 2020. Ensembl Genomes 2020-Enabling non-vertebrate genomic research. Nucleic Acids Res. 48 (D1):D689-D695.

Ismail, I. A., and Able, A. J. 2016. Secretome analysis of virulent Pyrenophora teres f. teres isolates. Proteomics 16:2625-2636.

Ismail, I. A., and Able, A. J. 2017. Gene expression profiling of virulence-associated proteins in planta during net blotch disease of barley. Physiol. Mol. Plant Pathol. 98:69-79.

Jalli, M. 2011. Sexual reproduction and soil tillage effects on virulence of Pyrenophora teres in Finland. Ann. Appl. Biol. 158:95-105.

Koladia, V. M., Faris, J. D., Richards, J. K., Brueggeman, R. S., Chao, S., and Friesen, T. L. 2017a. Genetic analysis of net form net blotch resistance in barley lines CIho 5791 and Tifang against a global collection of P. teres f. teres isolates. Theor. Appl. Genet. 130:163173.

Koladia, V. M., Richards, J. K., Wyatt, N. A., Faris, J. D., Brueggeman, R. S., and Friesen, T. L. 2017b. Genetic analysis of virulence in the Pyrenophora teres f. teres population BB25 $\times$ FGOH04Ptt-21. Fungal Genet. Biol. 107:12-19.

Laluk, K., and Mengiste, T. 2010. Necrotroph attacks on plants: Wanton destruction or covert extortion? Arabidopsis Book 8:e0136.

Lightfoot, D. J., Mcgrann, G. R. D., and Able, A. J. 2017. The role of a cytosolic superoxide dismutase in barley-pathogen interactions. Mol. Plant Pathol. 18:323-335.

Liu, Z., Holmes, D. J., Faris, J. D., Chao, S., Brueggeman, R. S., Edwards, M. C., and Friesen, T. L. 2015. Necrotrophic effectortriggered susceptibility (NETS) underlies the barley-Pyrenophora teres f. teres interaction specific to chromosome $6 \mathrm{H}$. Mol. Plant Pathol. 16:188-200.

Liu, Z. H., Zhong, S., Stasko, A. K., Edwards, M. C., and Friesen, T. L. 2012. Virulence profile and genetic structure of a North Dakota population of Pyrenophora teres $\mathrm{f}$. teres, the causal agent of net form net blotch of barley. Phytopathology 102:539-546.

Love, M. I., Huber, W., and Anders, S. 2014. Moderated estimation of fold change and dispersion for RNA-seq data with DESeq2. Genome Biol. 15:550.

Macho, A. P., and Zipfel, C. 2014. Plant PRRs and the activation of innate immune signaling. Mol. Cell 54:263-272.

Martin, A., Moolhuijzen, P., Tao, Y., McIlroy, J., Ellwood, S. R., Fowler, R. A., Platz, G. J., Kilian, A., and Snyman, L. 2020. Genomic regions associated with virulence in Pyrenophora teres f. teres identified by genome-wide association analysis and biparental mapping. Phytopathology 110:881-891.

Molina, A., Segura, A., and García-Olmedo, F. 1993. Lipid transfer proteins (nsLTPs) from barley and maize leaves are potent inhibitors of bacterial and fungal plant pathogens. FEBS Lett. 316:119-122.

Moolhuijzen, P. M., Muria-Gonzalez, M. J., Syme, R., Rawlinson, C., See, P. T., Moffat, C. S., and Ellwood, S. R. 2020. Expansion and conservation of biosynthetic gene clusters in pathogenic Pyrenophora spp. Toxins (Basel) 12:242.

Mur, L. A. J., Simpson, C., Kumari, A., Gupta, A. K., and Gupta, K. J. 2017. Moving nitrogen to the centre of plant defence against pathogens. Ann. Bot. 119:703-709.

Murray, G. M., and Brennan, J. P. 2010. Estimating disease losses to the Australian barley industry. Australas. Plant Pathol. 39:85-96.

Neuser, J., C. C. Metzen, B. H. Dreyer, C. Feulner, J. T. van Dongen, R. R. Schmidt and J. H. M. Schippers 2019. HBI1 mediates the tradeoff between growth and immunity through its impact on apoplastic ROS homeostasis. Cell Rep. 28:1670-1678.

Ngou, B. P. M., Ahn, H.-K., Ding, P., and Jones, J. D. G. 2020. Mutual potentiation of plant immunity by cell-surface and intracellular receptors. bioRxiv. 2020.2004.2010.034173.

Pandelova, I., Betts, M. F., Manning, V. A., Wilhelm, L. J., Mockler, T. C., and Ciuffetti, L. M. 2009. Analysis of transcriptome changes induced by Ptr ToxA in wheat provides insights into the mechanisms of plant susceptibility. Mol. Plant 2:1067-1083.

Petersen, T. N., Brunak, S., von Heijne, G., and Nielsen, H. 2011. SignalP 4.0: Discriminating signal peptides from transmembrane regions. Nat. Methods 8:785-786.

Postel, S., Küfner, I., Beuter, C., Mazzotta, S., Schwedt, A., Borlotti, A., Halter, T., Kemmerling, B., and Nürnberger, T. 2010. The multifunctional leucine-rich repeat receptor kinase BAK1 is implicated in Arabidopsis development and immunity. Eur. J. Cell Biol. 89:169174.

Quevillon, E., Silventoinen, V., Pillai, S., Harte, N. Mulder, R. Apweiler, and Lopez, R. 2005. InterProScan: protein domains identifier. Nucleic Acids Res. 33:W116-W120. 
Richards, J. K., Friesen, T. L., and Brueggeman, R. S. 2017. Association mapping utilizing diverse barley lines reveals net form net blotch seedling resistance/susceptibility loci. Theor. Appl. Genet. 130:915-927.

Shjerve, R. A., Faris, J. D., Brueggeman, R. S., Yan, C., Zhu, Y., Koladia, V., and Friesen, T. L. 2014. Evaluation of a Pyrenophora teres $\mathrm{f}$. teres mapping population reveals multiple independent interactions with a region of barley chromosome $6 \mathrm{H}$. Fungal Genet. Biol. 70:104-112.

Sperschneider, J., Dodds, P. N., Gardiner, D. M., Singh, K. B., and Taylor, J. M. 2018. Improved prediction of fungal effector proteins from secretomes with EffectorP 2.0. Mol. Plant Pathol. 19:2094-2110.

Syme, R. A., Martin, A., Wyatt, N. A., Lawrence, J. A., Muria-Gonzalez, M. J., Friesen, T. L., and Ellwood, S. R. 2018. Transposable element genomic fissuring in Pyrenophora teres is associated with genome expansion and dynamics of host-pathogen genetic interactions. Front. Genet. 9:130.

van Ooijen, G., Mayr, G., Kasiem, M. M., Albrecht, M., Cornelissen, B. J., and Takken, F. L. 2008. Structure-function analysis of the NB-ARC domain of plant disease resistance proteins. J. Exp. Bot. 59:1383-1397.

Wallwork, H., Butt, M., and Capio, E. 2016. Pathogen diversity and screening for minor gene resistance to Pyrenophora teres f. teres in barley and its use for plant breeding. Australas. Plant Pathol. 45:527-531.

Xu, X. M., Lin, H., Maple, J., Björkblom, B., Alves, G., Larsen, J. P., and Møller, S. G. 2010. The Arabidopsis DJ-1a protein confers stress protection through cytosolic SOD activation. J. Cell Sci. 123:1644-1651. 